\title{
Value of thermal sensibility testing in leprosy diagnosis in the field-field trial of a pocket device*
}

\author{
H SRINIVASAN $\dagger \&$ B STUMPE $\ddagger$ \\ $\dagger$ Central JALMA Institute for Leprosy, Agra, India; $\ddagger$ European \\ Organization for Nuclear Research (CERN), Geneva, Switzerland
}

\section{Accepted for publication 28 April 1989}

\begin{abstract}
Summary A handy thermal sensibility testing device has been developed and field tested in different centres in Africa and India. The device performed satisfactorily under field conditions and made testing for thermal sensibility in the field practicable and easy. Examination of the results of testing 260 persons, most of them having a few lesions of early leprosy, showed that the expected increase in the rate of diagnosis of sensory impairment in the skin lesions, and so in the diagnosis of leprosy, would be about $15-25 \%$ when thermal sensibility testing using this device was added to the other sensibility tests routinely used in the field. Regular use of this device in the field will help to bring more leprosy patients under treatment than at present.
\end{abstract}

\section{Introduction}

Eliciting impairment in sensibility in a suggestive skin lesion ('patch') is a vital part of clinical examination of a person suspected of having leprosy. In such cases, demonstration of impaired sensibility in the skin lesion clinches the diagnosis of leprosy. It is customary to test for perception of pain and/or touch for this purpose. Any method of sensibility testing will be all right in the later stages of the disease because by then all modalities of sensation will have been impaired. In the early stages, the patch may show dissociated loss of sensibility and in such cases perception of pain and warmth is impaired earlier than that of touch or other modalities. ${ }^{1-4}$ However, testing for thermal sensibility impairment is not routinely carried out even in the clinic because the method described for testing, such as using test-tubes with hot and cold water, is cumbersome and time consuming.

The modalities of pain and thermal sensations are subserved through the same, unmyelinated and thinly myelinated (C and A) fibre systems. ${ }^{5-7}$ Since infection of individual Schwann cells with Mycobacterium leprae is likely to be a random phenomenon, we may expect 'thermal fibres' to be affected first in some cases and 'pain fibres' first in others. By not being able to test for impaired thermal sensibility we will be missing those cases with initial impairment of only that modality. If we can test for impairment of thermal sensibility, particularly in the field where most leprosy work is being carried out, we should be able to identify those with isolated thermal sensibility impairment and bring them under treatment at that stage.

* Lepra wishes to thank the World Health Organization for permission to reproduce this article from the $\mathrm{WHO}$ Bulletin. 
In view of this, WHO has been helping to develop a thermal sensibility tester suitable for use in the field. Such a tester should be light, easy for field personnel to carry and operate, sturdy, small, not too expensive, capable of attaining a predetermined temperature in a short time and should not consume too much power. The first prototype of such a device was fabricated and field tested in a number of centres in Africa, Asia and South America. Based on that experience an improved second prototype was developed and limited field testing was carried out for assessing the suitability, acceptability and sturdiness of the device. Based on feedback information from the use of these two prototypes, a third and final prototype has been developed. Limited numbers of this device were distributed to some centres in Africa and Asia for testing in the field in order to assess the extent of improvement in diagnostic sensitivity by doing thermal sensibility testing, in addition to the sensibility tests customarily used in these centres. The results of this exercise are reported here.

\section{The device}

An earlier prototype device (prototype I) used the body of a pen torch on which a relatively sophisticated electronic head was mounted to control the warm end to a present temperature of $40^{\circ} \mathrm{C}$. Field testing using prototype $\mathrm{I}$ had shown the potential value of using such a device for the diagnosis of early leprosy, but it was realized that the technical specification, particularly temperature control, and the robustness of the device had to be improved. To cope with these problems it was decided to produce prototype II which was completely different from prototype I. Prototype II had the warm tip temperature as a function of the ambient temperature. Experimenting with a new type of ceramic semiconductor material, it was found possible to develop a special heating element able to control its own temperature according to the desired specification. The advantages of this heating element were simpler and more reliable electronics, smaller power consumption, faster warm-up time, capacity to perform under a range of temperature conditions and lower cost. Prototype III evolved from the previous model after further improving the 'on-off' switching mechanism and the hot tip design. The variable hot tip temperature was chosen so that it was always greater than the skin temperature even for very low ambient temperatures $\left(10^{\circ} \mathrm{C}\right)$ but not excessively high (to avoid burning) at very high ambient temperatures $\left(45^{\circ} \mathrm{C}\right)$.

Details of the prototype III device are given in Table 1 and in Figures 1 to 4 . The device is shown in Figure 5.

\section{Results}

The three prototypes were tested in the field as and when they were developed. Prototype III was field tested in Africa and India to find out the extent of improvement in diagnostic sensitivity using thermal sensibility testing and to satisfy ourselves that the device was not degraded by use.

Data covering 319 people participating in this field trial of prototype III were received from 6 centres ( 3 from Africa and 3 from India). The findings from one centre regarding 59 people were non-informative but the findings on the remaining 260 people from the other 5 centres are presented here.

The study included both sexes and practically all ages. The duration of patches in these 260 people was under one year for 172 people, one to two years for 31 and more than two years for 17 . Information was not available for 40 people.

The clinical diagnosis of the skin lesion is given in Table 2 . In over $80 \%$ of instances the clinical diagnosis was tuberculoid, indeterminate or 'suspicious' and of all the patients about one half had single lesions while the remainder had two or more. Sensibility testing was done on one lesion in 184 persons, on two lesions in 41 and on three lesions in 35.

Sensibility testing for touch was routinely used in all the centres and the pinprick test for pain perception was also in use in 4 of the 5 centres. Thus all three modalities of sensation were tested on 
Table 1. Thermal sensibility tester technical specifications.

Battery types

Battery size

Power consumption

(still air)

Typical hot tip temperature

Recommended working temp. examinations

Time bef ore use

after power on

Power ON-OFF

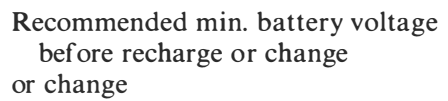

Dimensions

Weight
Preferably rechargeable $1 \cdot 2 \mathrm{~V}$ nickel-cadmium types OR $1.5 \mathrm{~V}$ good quality alkaline

\section{AA-R6-UM3-MIGNON}

(approx.)

$240 \mathrm{~mA}$ at ambient temp. $15^{\circ} \mathrm{C}$

$200 \mathrm{~mA}$ at ambient temp. $25^{\circ} \mathrm{C}$

$120 \mathrm{~mA}$ at ambient temp. $45^{\circ} \mathrm{C}$

$45^{\circ} \mathrm{C}$ at ambient temp. $15^{\circ} \mathrm{C}$

$50^{\circ} \mathrm{C}$ at ambient temp. $25^{\circ} \mathrm{C}$

$60^{\circ} \mathrm{C}$ at ambient temp. $45^{\circ} \mathrm{C}$

$10^{\circ} \mathrm{C}$ to $45^{\circ} \mathrm{C}$ ambient temp.

15 sec. for amb. temp. $>15^{\circ} \mathrm{C}$

30 sec. for amb. temp. $<15^{\circ} \mathrm{C}$

POWER IS ON: When button end is turned fully clockwise until end stop.

POWER IS OFF: When button end is turned anticlockwise until dotted line is visible.

$1 \mathrm{~V}$ each battery

Tip size $7 \mathrm{~mm}$ diameter.

Body length $133 \mathrm{~mm}$.

Body diameter $22 \mathrm{~mm}$.

Area exposed to the skin $38.5 \mathrm{~mm}^{2}$.

$83 \mathrm{~g}$ without batteries

210 people only, although thermal sensibility testing using the tester device was carried out on all 260 people.

First, the findings are given taking the skin lesion as the unit of observation and then they are given taking the individual as the unit of observation.

\section{Observations on skin lesions}

Pain, touch and thermal sensibility had all been tested on 263 skin lesions of 210 people. Information regarding 8 lesions (on 6 people) was incomplete and therefore analysis of comparison of all three modalities of sensation is based on 255 lesions in 204 persons (Table 3).

The capacity of the different modalities of sensory loss and their combinations to identify early lesions is shown in Figure 6.

\section{Observations regarding persons}

The above observations relate to individual skin lesions. It will be evident that when more than one lesion is tested in a person, that person would be identified as having sensory impairment (and so as a case of leprosy) even if it were demonstrated in only one of the lesions. Therefore the data were reexamined keeping the person, and not the lesion, as a unit. As mentioned earlier, four of the five centres routinely used tests for pain and touch sensibility, whereas one centre used only touch 
Figure 1

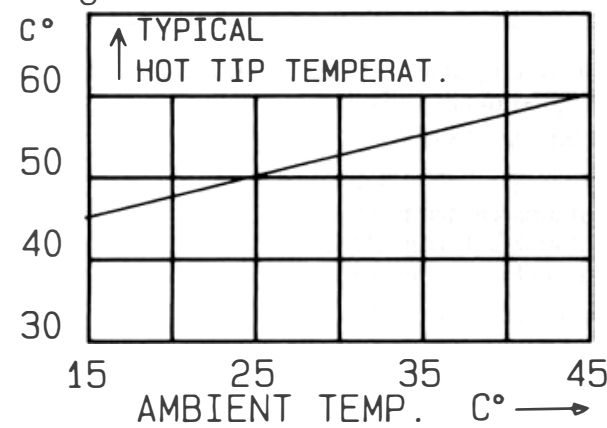

Figure 3

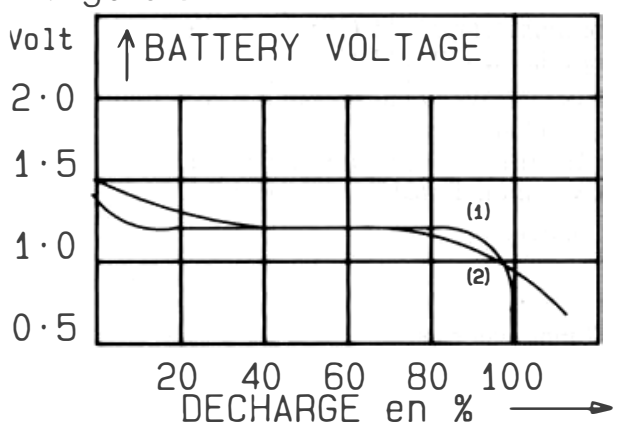

(1) Typical battery discharge characteristics for rechargeable "NICKEL-CADMIUM" batteries .

(2) non rechargeable "ALKALINE-MANGANESE" battery types.

The use of rechargeable batteries is recommended for following reasons:

- lower operational costs

- flatter decharge characteristic

- smaller waste disposal problems Minimum battery voltage before change or recharge 1V. (Each battery).
Figure 2

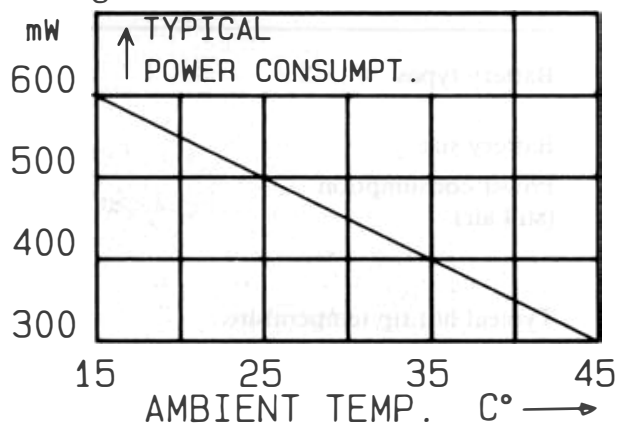

Figure 4

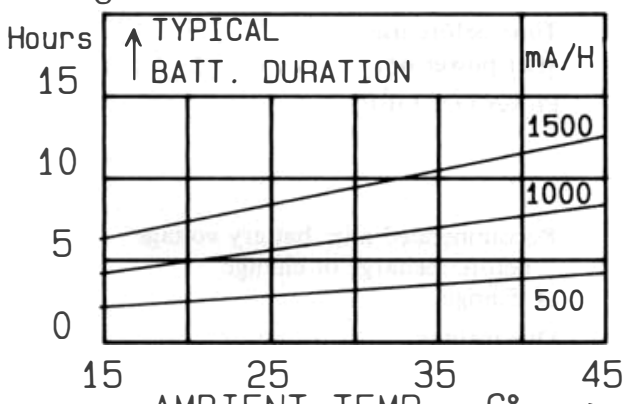

AMBIENT TEMP. $\quad \mathrm{C}^{\circ} \longrightarrow$

- Typical battery duration at various ambient temperatures and different capacity.

- A standard rechargeable battery has a capacity of $500 \mathrm{~mA}$ /Hours.

- A good quality ALKALINE battery can have a capacity of $1500 \mathrm{~mA} /$ Hours.

EXAMPLE :

* At $30 \mathrm{C}^{\circ}$ a rechargeable battery ( $500 \mathrm{~mA} / \mathrm{H}$ ) will last 3.1 hours.

* At $30 \mathrm{C}^{\circ}$ a standard Alkaline battery ( $1000 \mathrm{~mA} / \mathrm{H}$ ) will last 6.2 hours.

( Mean battery voltage 2,5v)

Figures 1-4.

sensibility for recognizing sensory impairment. Table 4 shows the pooled findings from the four centres using routine pain and touch sensibility tests.

The capacity of the different modalities of sensory loss and their.combinations to identify early cases of leprosy is shown in Figure 7.

\section{Discussion}

Successful leprosy control depends on effective treatment with multidrug therapy ${ }^{8}$ and early 


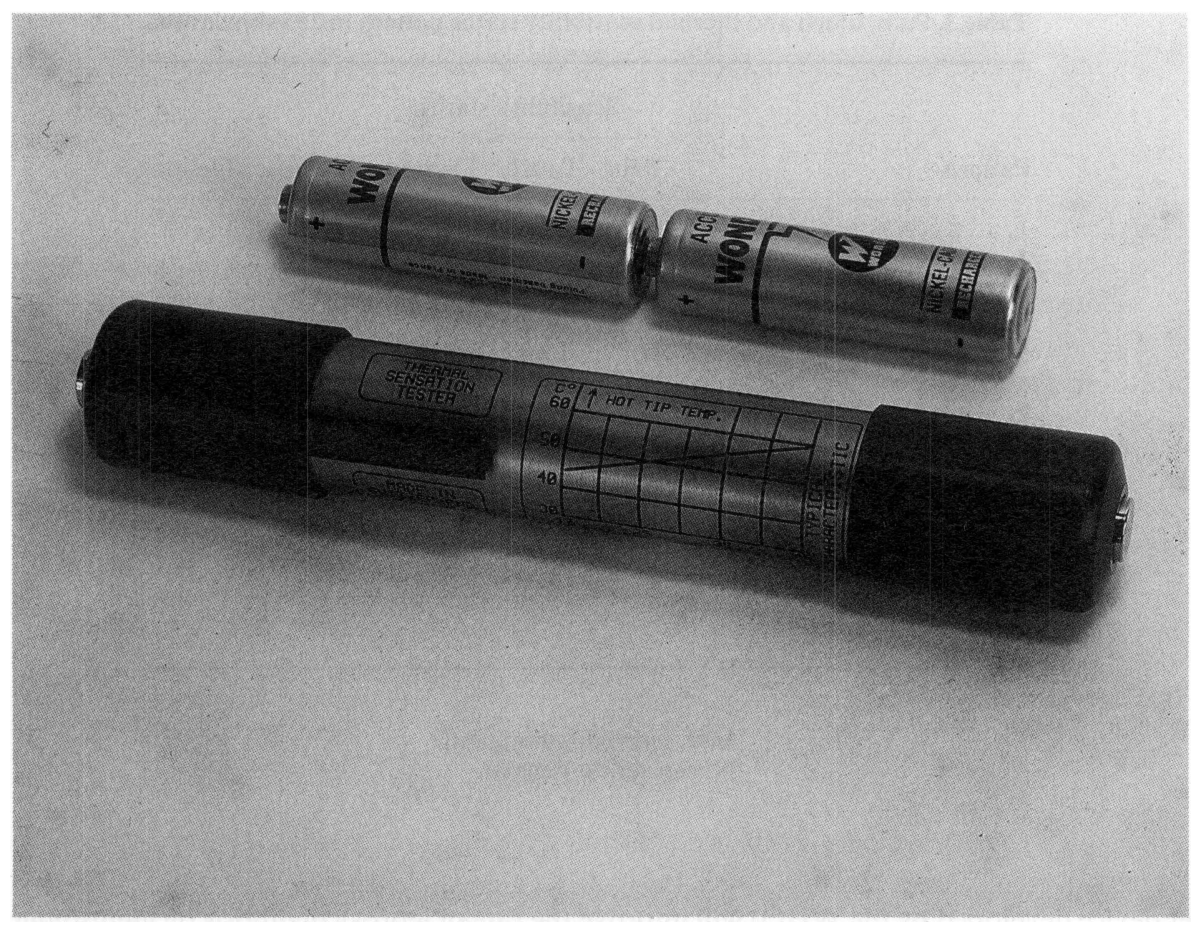

Figure 5. Thermal sensibility tester.

Table 2. Clinical diagnosis of skin lesions

\begin{tabular}{lc}
\hline Clinical diagnosis & Number of people \\
\hline 'Suspicious' & 51 \\
Indeterminate & 22 \\
Tuberculoid & 64 \\
Tuberculoid (borderline) & 79 \\
Borderline & 5 \\
Lepromatous (borderline) & 9 \\
Lepromatous & 29 \\
Not recorded & 1 \\
\hline All diagnoses & 260 \\
\hline
\end{tabular}

diagnosis of all cases. The addition of thermal sensibility testing to the other sensibility testing procedures in routine use in the field may be expected to meet the need for improving the rate of leprosy diagnosis and for bringing additional numbers of patients under effective treatment. This has not been possible so far because the method of testing for thermal sensibility in the field was not practicable.

The present investigation was not an academic enquiry about the pattern of impairment of thermal or other sensibility. It was a pragmatic exercise with the operational aims of finding answers to two questions: (i) To what extent the addition of thermal sensibility testing in the field (using the 
Table 3. Pain, touch and thermal sensibility status pattern in 255 skin lesions

\begin{tabular}{llllr}
\hline \multirow{2}{*}{ Pattern } & \multicolumn{2}{c}{ Sensibility status } & \\
\cline { 2 - 3 } & Pain & Touch & Thermal & Number of lesions \\
\hline 1 & Imp. & Imp. & Imp. & 132 \\
2 & Imp. & Imp. & N & 8 \\
3 & Imp. & N & Imp. & 13 \\
4 & Imp. & N & N & 7 \\
5 & $\mathrm{~N}$ & Imp. & Imp. & 6 \\
6 & $\mathrm{~N}$ & Imp. & N & 3 \\
7 & $\mathrm{~N}$ & $\mathrm{~N}$ & Imp. & 27 \\
Lesions with impairments & 160 & 149 & 173 & 196 \\
Lesions with no impairments: & & & & 59 \\
Pattern 8 & $\mathrm{~N}$ & $\mathrm{~N}$ & $\mathrm{~N}$ & 255 \\
\hline Total lesions tested & & & & \\
\hline
\end{tabular}

Imp, sensibility impaired.

$\mathrm{N}$, sensibility normal.

tester device developed by the WHO) will improve the rate of leprosy diagnosis by identifying cases of isolated impairment of thermal sensibility in the skin lesions? (ii) Is it feasible to use this tester device in the field for this purpose?

In order to find answers to these questions, the device had to be tested by different people in different parts of the world, under a variety of field conditions. Therefore a multicentric trial was planned and the participants were requested to carry out thermal sensibility testing in addition to the tests they were routinely using in the field. It was gratifying to note that clear answers to both the questions have emerged from this study.

\section{Performance of the device}

All the investigators felt that the performance of the device was quite satisfactory. It was easy to carry and it made thermal sensibility testing simple and feasible in the field. The size of the warm end ( $7 \mathrm{~mm}$ diameter and $38.5 \mathrm{~mm}^{2}$ area) was suitable for testing all but very small lesions. Power consumption was not excessive and ordinary leak-proof pen torch cells, which were used in most centres, needed to be changed after testing 50-70 people, dependent on the type of battery and ambient temperature. However, when the ambient temperature was very low, in the range of $10^{\circ}-$ $15^{\circ} \mathrm{C}$ or lower, it naturally took longer to warm up and the drain on the cells was heavy, making it difficult for some types of batteries to deliver the current needed during the warm-up period. This problem could be solved by using rechargeable batteries for which the unit cost per test is cheaper. When rechargeable batteries are used the additional investment cost is expected to be about US $\$ 25.00$ which would include the cost of a battery charger, two sets of two rechargeable batteries and a battery checker. The cost of the thermal tester will be around US $\$ 35.00$. A set of rechargeable batteries can be charged over 500 times which means that two sets can be used for over 50,000 examinations at the rate of 50 examinations per charge. The cost of electricity to charge for 1000 times $(\$ 2.00)$ together with the cost of the charger and battery checker is US $\$ 27.00$ which enables 

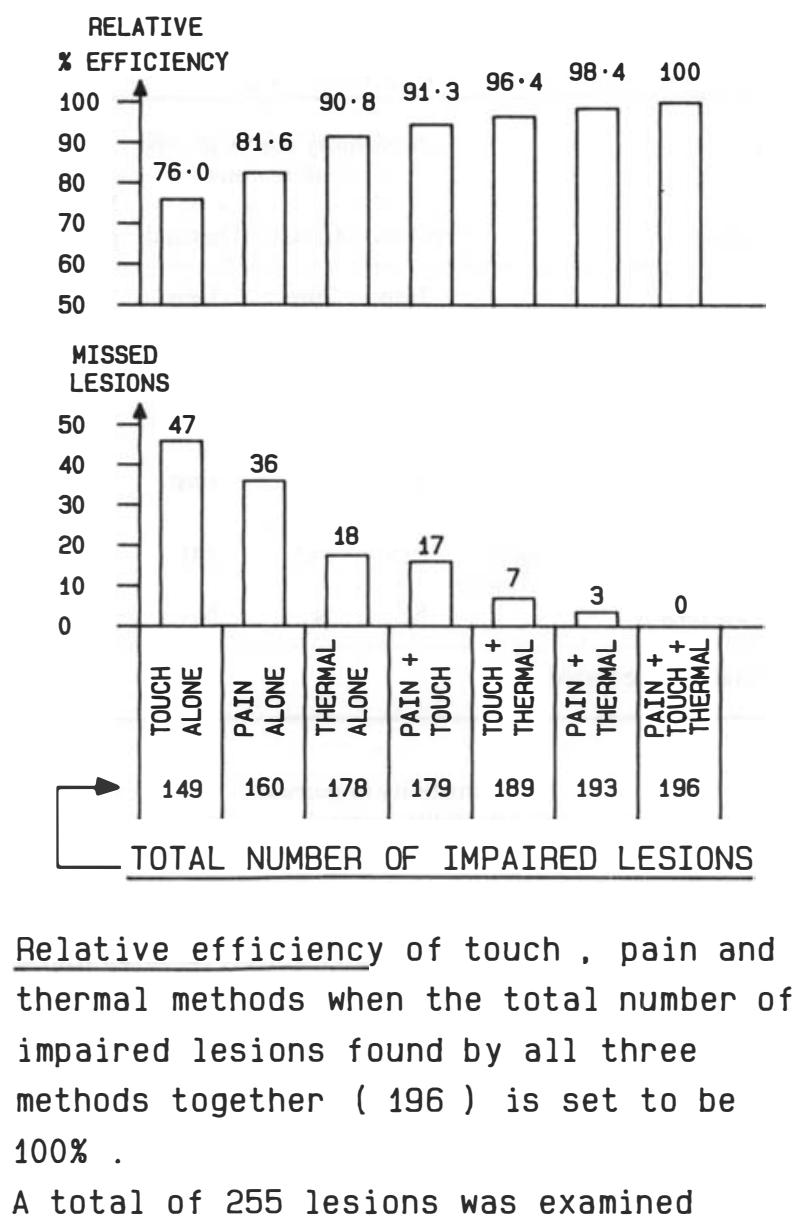

Figure 6.

the unit cost per examination to be limited to only $\$ 0.00054$. On the other hand, if non-rechargeable batteries are used, then at the rate of $\$ 1.00$ per set of 2 good quality batteries and at the rate of 70 examinations per set, the unit cost would be approximately $\$ 0.014$. Thus, the use of rechargeable batteries enables the cost to be reduced by a factor of about 26 . In addition, the use of rechargeable batteries markedly reduces the problem of waste disposal.

The other problem in the tester occurred when the ambient temperature was above $40^{\circ} \mathrm{C}$, then the temperature difference between the so-called 'cold' end and the 'warm' end was relatively less and it was not always easy to distinguish the 'cold' from the 'warm' end which was what the patient had to do in this test.

\section{Advantage of including thermal sensibility testing}

One may expect that inclusion of thermal sensibility testing would identify more people who had sensibility impairment, but so far there has been no way of knowing what this additional number is. In this study, the routine tests for light-touch and pin-prick pain identified 132 people as having 
Table 4. Pain, touch and thermal sensibility status in 204 people taking the individual as a unit of observation

\begin{tabular}{llllr}
\hline & \multicolumn{3}{c}{$\begin{array}{r}\text { Sensibility status in any } \\
\text { or all lesions }\end{array}$} \\
\cline { 2 - 4 } Pattern & Pain & Touch & Thermal & $\begin{array}{r}\text { No. of } \\
\text { people }\end{array}$ \\
\hline 1 & Imp. & Imp. & Imp. & 102 \\
2 & Imp. & Imp. & N & 6 \\
3 & Imp. & N & Imp. & 11 \\
4 & Imp. & N & N & 6 \\
5 & N & Imp. & Imp. & 4 \\
6 & N & Imp. & N & 3 \\
7 & N & N & Imp. & 24 \\
People with impairment & I25 & 115 & 141 & 156 \\
People with no impairment: & & & & \\
Pattern 8 & $\mathrm{~N}$ & $\mathrm{~N}$ & $\mathrm{~N}$ & 48 \\
\hline Total people tested & & & & 204 \\
\hline
\end{tabular}

Imp, sensibility impaired.

$\mathrm{N}$, sensibility normal.

sensory impairment (Table 4, patterns 1-6) and 72 (Table 4, patterns 7 and 8 ) as not having sensory impairment. Thermal sensibility testing, using the tester device, revealed that 24 of these 72 people $(33 \%)$ had in fact impaired (thermal) sensibility (pattern 7). The addition of thermal sensibility testing thus led to a substantial improvement in the rate of diagnosis, from 132 to 156, i.e. by about $15 \%$. It appears that we can improve the rate of diagnosis by about $10-20 \%$ by adding thermal sensibility testing to the other tests routinely used in the field. It will therefore be worthwhile to do so.

Comparing the relative efficacy of touch and thermal sensibility testing, we find that of the 156 patients with one or other type of sensory loss only $115(73.7 \%)$ were identified as having sensory deficit by testing for touch perception, whereas thermal sensibility testing identified $141(90 \cdot 4 \%)$ as having sensory deficit. The addition of thermal sensibility improved the rate of diagnosis substantially, from 115 to 141 , i.e. by $18 \%$ (Table 4 ). It should also be noted that of the 150 people identified as having impaired sensibility for either light-touch or thermal (patterns 1 to 3 and 5 to 7 ), isolated loss of perception of light-touch was found in only 9 (pattern 2 and 6) while this modality was spared in as many as 35 persons (patterns 3 and 7). It is clear that testing for touch is the less sensitive of the two tests for assessing sensibility status in leprosy lesions.

Pinprick pain perception test is commonly used in the field for identifying sensory impairment in lesions suspected to be due to leprosy. Comparing the relative efficacy of pinprick and thermal sensibility tests, we find that of the 156 persons with one or other type of sensory loss, $125(80 \cdot 1 \%)$ had loss of pain, whereas testing for thermal sensibility identified $141(90 \cdot 4 \%)$ as having impaired sensibility. Again, taking only these two tests into account, it is seen from Table 4 that 12 people showed only loss of pinprick pain perception (patterns 2 and 4 ) and 28 showed only loss of thermal sensibility (patterns 5 and 7) in their lesions. Thermal sensibility testing alone would have missed the former 12 cases and pinprick test alone would have missed the latter 28 cases. Lesion-wise a substantial number of those that gave a negative result to pinprick testing, no loss of pain, had impaired thermal sensibility. Notwithstanding the above, the pinprick has the merit of being extremely cheap and simple. Hence we feel it should continue to be used. 

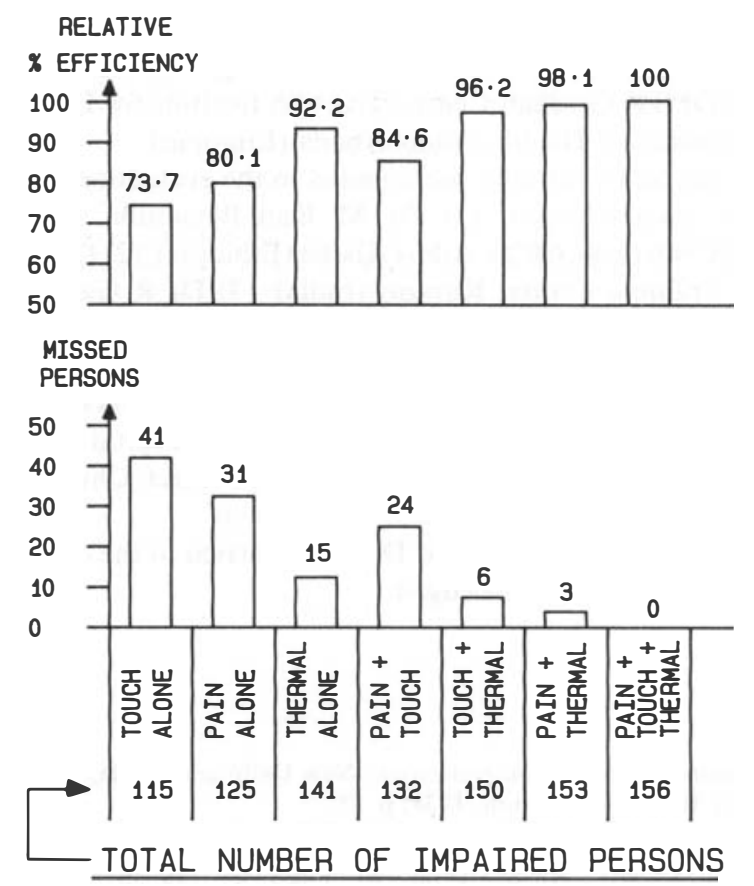

Relative efficiency of touch, pain and thermal methods when the total number of impaired persons found by all three methods together (156) is set to be 100\%.

\section{A total of 204 persons was examined}

Figure 7.

\section{Conclusion}

From this multicentric field trial we can therefore conclude that the addition of thermal sensibility testing increased the relative efficiency by up to $25 \%$, depending on which combination of tests were used. The thermal sensibility tester developed and tested in this trial will therefore be a suitable instrument for use in the field for this purpose.

\section{Acknowledgments}

The development and field testing of the thermal tester were supported by the Leprosy Unit, Division of Communicable Diseases, WHO, Geneva.

The contributions of the following investigators who participated in the evaluation of the final version of the tester is gratefully acknowledged: (1) Dr M D Gupte, Central JALMA Institute for Leprosy Field Unit for Epidemiology of Leprosy, Madras (India); (2) Dr N N'Deli, Institute Raoul 
Follereau D'Adzopé, Adzopé (Côte d'Ivoire); (3) Dr V K Pannikar, Schieffelin Leprosy Research and Training Centre, Karigiri (India); (4) Dr J M Ponnighaus, LEPRA Evaluation Project, Chilumba (Malawi); (5) Dr B K Girdhar, Central JALMA Institute for Leprosy, Agra (India); and (6) Mr Tadele Tedla, Ministry of Health, Addis Abada (Ethiopia).

The contribution of the following who participated in the evaluation of the earlier versions of the tester is gratefully acknowledged: (1) Dr M Becx-Bleumink, All Africa Leprosy and Rehabilitation Training Centre (ALERT), Addis Ababa (Ethiopia); (2) Dr M Christian, Schieffelin Leprosy Research and Training Centre, Karigiri (India); (3) Dr R Ganapati, Bombay Leprosy Project, Bombay (India); (4) Dr Lim Kuan Joo, National Leprosy Control Centre, Sungai Buluh (Malaysia); (5) Dr P N Neelan, Central Leprosy Teaching and Research Institute, Chingleput (India); (6) Dr J O Nyawalo, Alupe Leprosy Centre, Busia (Kenya); (7) Dr P Ochasanond, Ministry of Public Health, Bangkok (Thailand); (8) Dr D Opromolla, Hospital "Lauro de Souza Lima", Bauru (Brazil); (9) Dr J M Ponnighaus, LEPRA Evaluation Project, Chilumba (Malawi); and (10) Dr M Zuniga, Instituto de Biomedicina, Caracas (Venezuela).

The contributions of Mr M J O'Regan and Dr H Sansarricq in the development of the earlier versions of the tester is gratefully acknowledged.

\section{References}

1 Muir, E. Leprosy. Diagnosis, treatment and prevention. New Delhi and Simla, India, Indian Council of the British Empire Leprosy Relief Association, 1938; p. 75.

2 Cochrane, R.G. In: Leprosy in theory and practice, Bristol, John Wright, 1959; Chapter 10.

3 Antia, NH et al. Clinical, electrophysological, quantitative, histologic and ultrastructural studies of the index branch of the radial cutaneous nerve in leprosy. 1. Preliminary report. Int J Lepr, 1975; 43: 106-113.

4 Dharmendra. Le prosy. Bombay, Kothari Medical Publishing House, 1978; vol. 1, p. 50.

5 Keel, CA, Neil, E. In: Samson Wright's Applied Physiology, ELBS and Oxf ord University Press, London, 12th ed., 1971; Chapter six, p. 281.

${ }^{6}$ Dykes, RW. Sensory receptors, In: Reconstructive microsurgery, Daniel RK, Terzis JK, (eds), Little Brown \& Co., Boston, 1977; p. 331.

7 Lindblom, U, Ochoa, J . Somato-sensory function and dys function. In: Diseases of the nervous system-clinical neurobiology, Asbury AK, (ed), Saunders, Philadelphia, 1986; pp. 283-298.

8 WHO Study Group. Chemotherapy of leprosy for control programmes. Technical Report Series No. 675. WHO: Geneva 1982. 